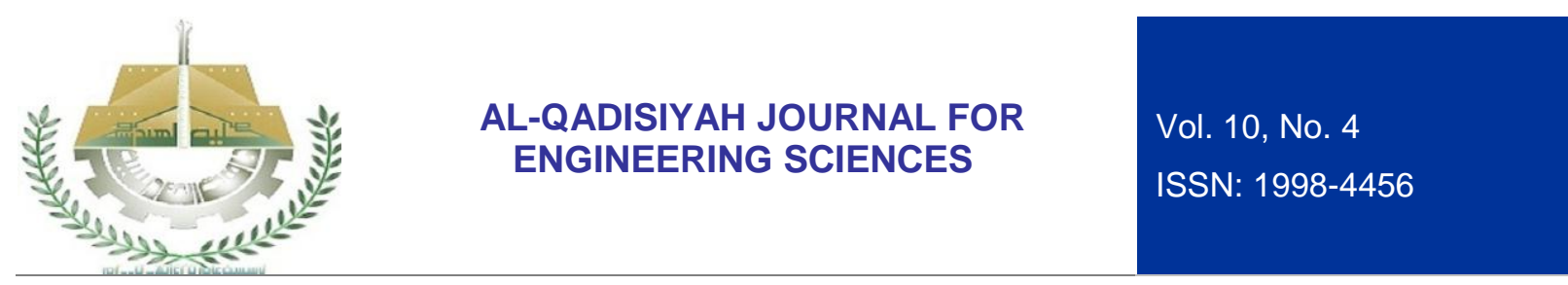

\title{
EFFECTS OF ROTATIONAL SPEED, CENTER DISTANCE AND DIAMETER RATIOS ON THE DYNAMIC RESPONSE OF PULLEY-BELT SYSTEM DEPENDS ON VIBRATION ANALYSIS
}

\author{
Dr. Ali Raad Hassan, \\ University of Technology, Mechanical Engineering Department, Baghdad. \\ E-mail: aliraad972@yahoo.com \\ Khalid Mohsin Ali, \\ University of Technology, Mechanical Engineering Department, Baghdad. \\ E-mail: khalid2771991@gmail.com
}

Received on 27 September 2017 Accepted on 13 December 2017 Published on 20 February 2018 DOI: 10.30772/qjes.v10i4.506

\begin{abstract}
This paper presents the dynamic response related to varying in indispensable parameters of pulley-belt system, a manufactured pulley- belt system has been built and experimental results have been obtained and analyzed accurately which reveal the effects of these parameters on indicated system. Manufactured system assembled from heavy steel structure, variable speed DC motor, speed measurement tool (tachometer), two shafts of $25 \mathrm{~mm}$ diameter, four pillow block ball bearings, $V$-belts and pulleys with different diameters $(10,15,20,25) \mathrm{cm}$. The fabricated system presents mechanical characteristics likes serial changing in rotational speed (500 to 2000) rpm, diameters ratios (1 to 2.5) and center distance $(27$ to 120) cm. accelerometer ADXL335 (3-axis) mounted on bearing brackets of drive and driven shafts and connected to Arduino type mega 2560 (microcontroller) which sending the data of vibration to the laptop in order to display it in Sigview software as a time and frequency domain band by FFT (fast fourier transform). Results showed the effects of change the values of rotational speed, center distance, and diameters ratios on vibration response of pulley-belt system.
\end{abstract}

Keywords: Dynamic response, FFT, Rotational speed, Diameters ratios, Center distance.

\section{INTRODUCTION}

Machines are very essential in our lives and it simplified the people's works. Now we use machine to the maximum extent in our daily activities, machines are becoming more complex, faster, intricate, and delicate and production process that are interlinked and automated. The efficiency of machines depends on many factors like raw materials, accuracy, enduringness, intelligent design...etc. Pulley-belt machinery is a basic part in any industry, which need to appropriate design and calculate pulley's diameters, belt length and radius ratio before manufacturing. In this paper an experimental investigation of the dynamic response of pulley-belt system were studied using vibration monitoring analysis the effects of pulley center distance, r.p.m, 


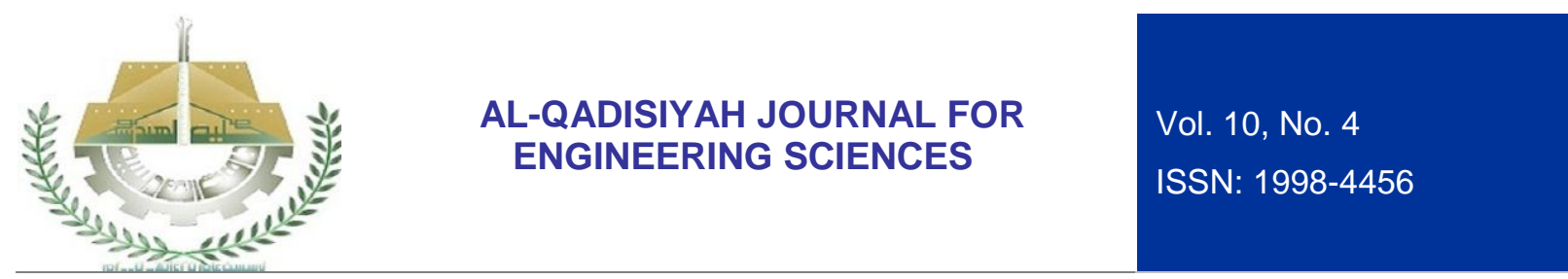

and diameter ratio which is the terrific tool to get the earliest warning that is beginning to occur in early stages of machines failure occurring may end up if we do not anything about earliest failures, in a sense, enables us to look inside the machine and see exactly what's going on. In a simply vibration analysis process need to sensor for vibration sensing (accelerometer), data acquisition to plotting recode data and a software to show the signals thus Examining, analyzing and diagnosing faults and defects in machine parts. A lot of experimental researches has specialized in vibration monitoring, the most important of them such as:

Hu Ding [1] Investigation Periodic responses of a pulley belt system with one-way clutch under inertia excitation, the effects of the intensity of the driving pulley excitation and the inertia excitation are studied. Moreover, numerical results demonstrate that the two excitations interact on the steady-state response, as well as the damping effect of the one-way clutch.

Indrajit Chowdhury [2] presented Dynamic response of machine foundations considering soil damping and embedment paper proposes a method based on which a number of such deficiencies as cited above can be circumvented. Chitresh Nayak et al [3] Presented design and development of machine fault simulator (MFS) for fault diagnosis. This paper show how to industry and construction of machine contains most parts that get damaged and vibrate over time in plurality machines like motor .Gregor $\mathbf{C}$ epona et al ${ }_{[4]}$ presented introduction of damping into the flexible multi body belt-drive model, Good agreement between the numerical result and the experimentally obtained data was found. Finally, the applicability of the belt-drive model was presented in a comparison with the pinned-pinned beam model. Chyuan-Jau Shieh ${ }_{[5]}$ studied the effect of angular speed on behavior of a V-belt drive system. this paper shows the effect of rotate speed on the 3D friction contact surface behavior between v-belt st $13 \mathrm{~mm}$ and pulley Abdulshakoor et al. [6] Used vibration analysis for faults in V-belt $13 \mathrm{~mm}$, three faults are used side-cut-out, side-cut-in and loose.

Mouleeswaran and Moorthy [7] monitored vibration for defect diagnosis on a machine tool (comprehensive case study). S.Ojha et al. ${ }_{[8]}$ investigation the performance monitoring of vibration in belt conveyor system, this paper presents the vibration related faults diagnosis and maintenance of belt conveyor system. S. R. Algule et al ${ }_{[9]}$ presented experimental study of unbalance in shaft rotor system using vibration signature analysis. Puneet Bansal et al ${ }_{[10]}$ deals with monitoring and analysis of vibration signal in turning machine with one type of cutting tool and sample (mild steel and brass). B. Kiran Kumar et al ${ }_{\text {[11] }}$ presented determination of unbalance in rotating machine using vibration signature analysis. Pravesh and Akhilesh ${ }_{\text {[12] }}$ focused on fault diagnosis of ball bearing using time domain analysis and fast Fourier transformation. Arko Djajadi et al ${ }_{[13]}$ Presented monitoring vibration of a model of rotating machine. The case study was a rotate shaft with balance and unbalance by add and reduce mass of balance. Sakshi Kokil et al [14] studied detection of fault in rolling element bearing using condition of monitoring by experimental approach. Dimitris et al [15] Practically studied maintenance topics of mechanical drivers and faults diagnosis of machine elements. This paper presents vibration monitoring using as a design technique, Results were taken from many experiments at different dimensions and values of center distance, radius ratio and speed, at constant tension $30 \mathrm{~N}$, and $\mathrm{V} 13$ belt type.

\section{EXPERIMANTAL SETUP AND VIBRATION MEASURMENT}

Machine was manufactured with personal experience by researchers, it consisted of heavy structure steel frame, steel pulleys, DC motor variable speed, shafts, pillow bearings, tachometer and tools for precision measurements as shown in figure 1. 

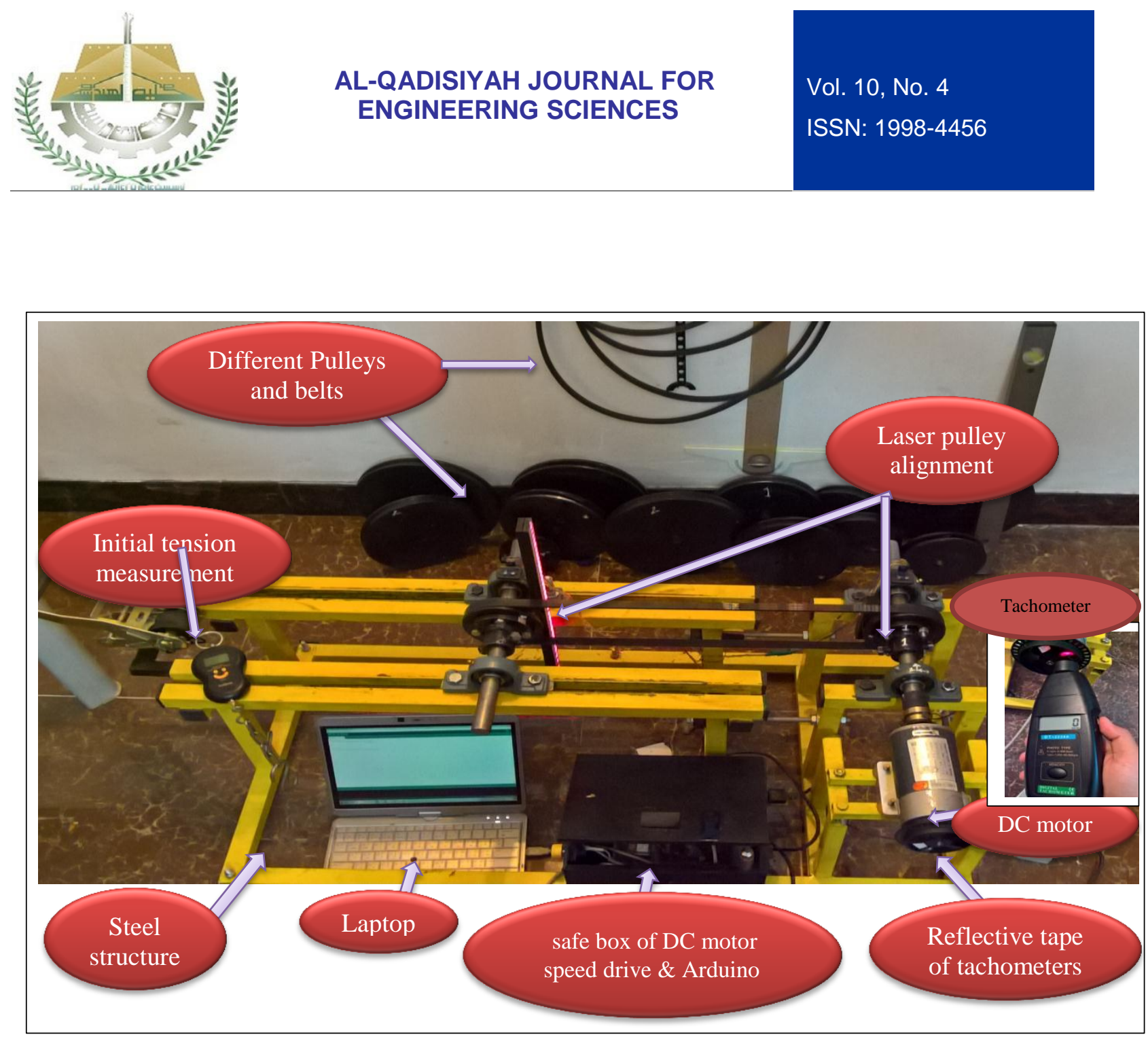

Figure 1: Details of system parts.

Vibration sensors ADXL335 (3axis accelerometer) [16] with sensitivity of $300 \mathrm{mv} / \mathrm{g}$, this sensor can read a range of $0.5 \mathrm{~Hz}$ to $1600 \mathrm{~Hz}$ for the $X$ and $Y$ axes, and a range of $0.5 \mathrm{~Hz}$ to $550 \mathrm{~Hz}$ for the $Z$ axis output, sensors mounted geometrically on bearing brackets of drive and driven shafts.Y-direction of sensor will be with axil direction of shaft .X and $Z$ will be radial on shaft horizontal and vertical respectively as show in Figure2 Sensors connected to Arduino type mega which have CPU $16 \mathrm{MHz}$ sending the data of vibration after calibration process to the laptop to display it in software model (Sigview) as a time and frequency domain band by FFT (fast Fourier transform). To know the magnitudes of rotate speeds need to rpm gauge (Tachometer DT-2234A) photo type with reflective tape on rotate parts as shown above. Initial tension should be at a constant value of $30 \mathrm{~N}$ in each cases, this value determined as installation tension (optimal) by the manufacturing company (Super Star belts), also this magnitude investigated by tensile test device and PIDANSYS, data of tensioned belt deals as hyper-elastic material by Moony-Revilin model. 

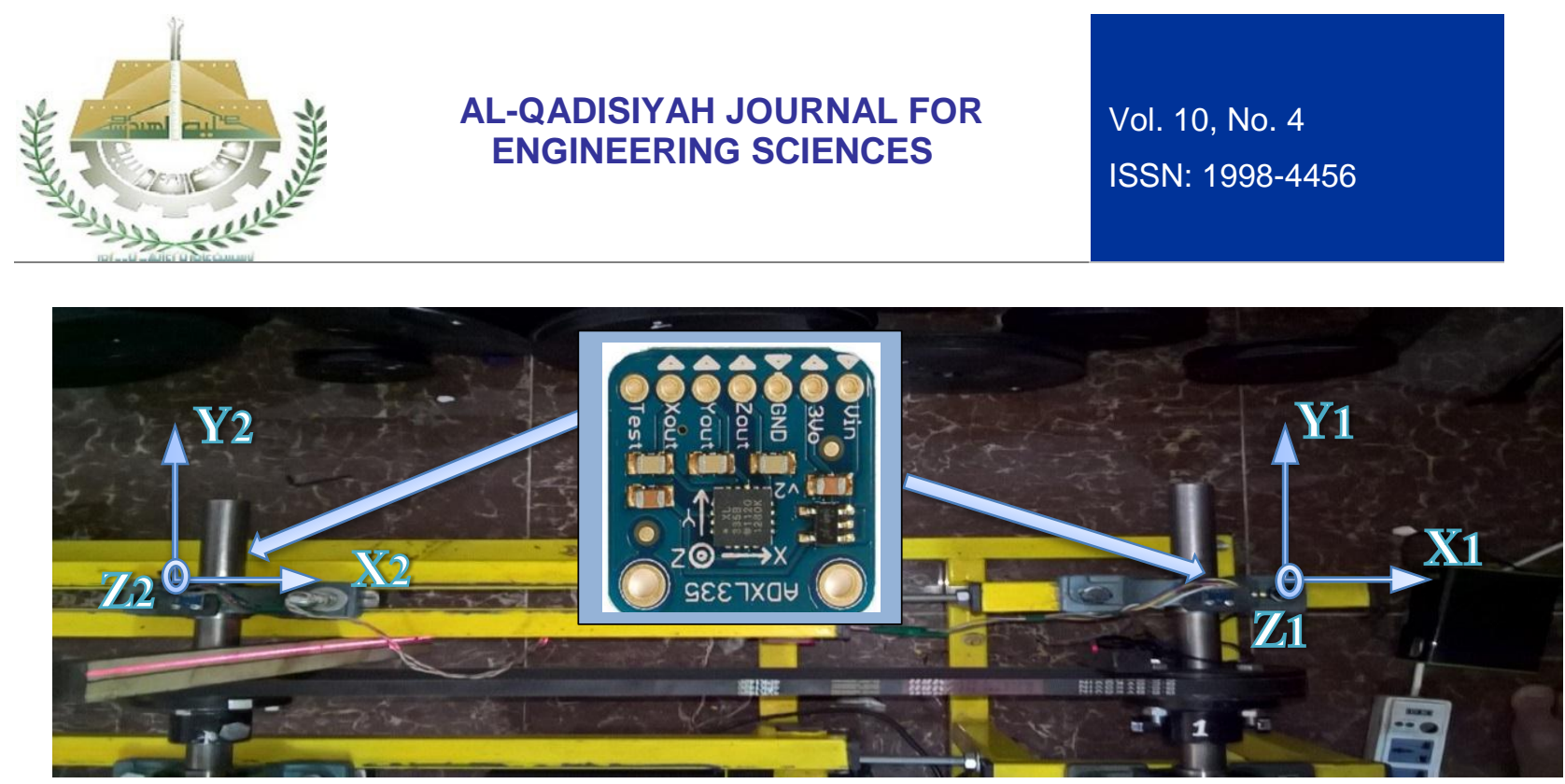

Figure 2: Two sensors ADXL335 geometrically positions.

\section{VIBRATIONS ANALYSIS}

Vibration can be used to detect and diagnose problems on rotating equipment ranging from electric motors to large crushing machines used for mining and processing. Because each part is in a case of motion has an individual frequency. FFT has important features to show for each part its frequency, also frequency of faults which are unavoidable due to the errors and accuracy in manufacturing or May temporarily develop in the system due to the operating conditions. The most encounter faults existing in the pulley belt system described in the following table ${ }_{[17]}$. Having in mind that the fundamental frequency is shaft revolution in rpm $1 \mathrm{X}$.

Table 1: Common faults in belt-pulley systems.

\begin{tabular}{|c|c|l|}
\hline Symptom & Frequency & \multicolumn{1}{|c|}{ Comments } \\
\hline Unbalance & $1 \mathrm{X}$ & Unbalance mass, misalignment belt \\
\hline Misalignment & $2 \mathrm{X}, 3 \mathrm{X}$ & Coupling \\
\hline Looseness 1 & $3 \mathrm{X}-10 \mathrm{X}$ radial & Structural looseness \\
\hline Looseness 2 & $0.5 \mathrm{X}, 1.5 \mathrm{X}, 2.5 \mathrm{X}, 3.5 \mathrm{X}$ & Excessive bearing unsteady \\
\hline resonance & $1 \mathrm{X}$ & Belt or structure resonance \\
\hline Bearings & $B P F O=f_{\text {outer }}=\frac{n}{2} f_{s}\left(1-\frac{B D}{P D} \cos \phi\right)$ & Ball pass frequency outer race \\
\cline { 2 - 4 } frequencies & $B P F I=f_{\text {trner }}=\frac{n}{2} f_{s}\left(1+\frac{B D}{P D} \cos \phi\right)$ & Ball pass frequency inner race \\
\cline { 2 - 4 } & $B S F=f_{\text {ball }}=f_{s} \frac{P D}{B D}\left[1-\left(1+\frac{B D}{P D} \cos \phi\right)^{2}\right]$ & Ball spin frequency \\
\cline { 2 - 4 } & $F T F=f_{\text {cage }}=\frac{1}{2} f_{s}\left(1-\frac{B D}{P D} \cos \phi\right)$ & Fundamental train frequency cage \\
\hline Worn or loose belt & $1 \mathrm{X}-4 \mathrm{X}$ of $\operatorname{Belt}$ frequency & Faults in belt , \\
\hline
\end{tabular}




\section{AL-QADISIYAH JOURNAL FOR ENGINEERING SCIENCES}

To recognize healthy conditions from bad or faulty conditions of operating machines, time domain waveform will be as shown in Figure 3. Faulty conditions waveform will give incomprehensible signal and more peaks in FFT at different frequencies. While at good conditions wave form will be consistent and sinusoidal often. While at a good conditions waveform will be consistent, sinusoidal often, and low and low number of peaks in FFT will appear.
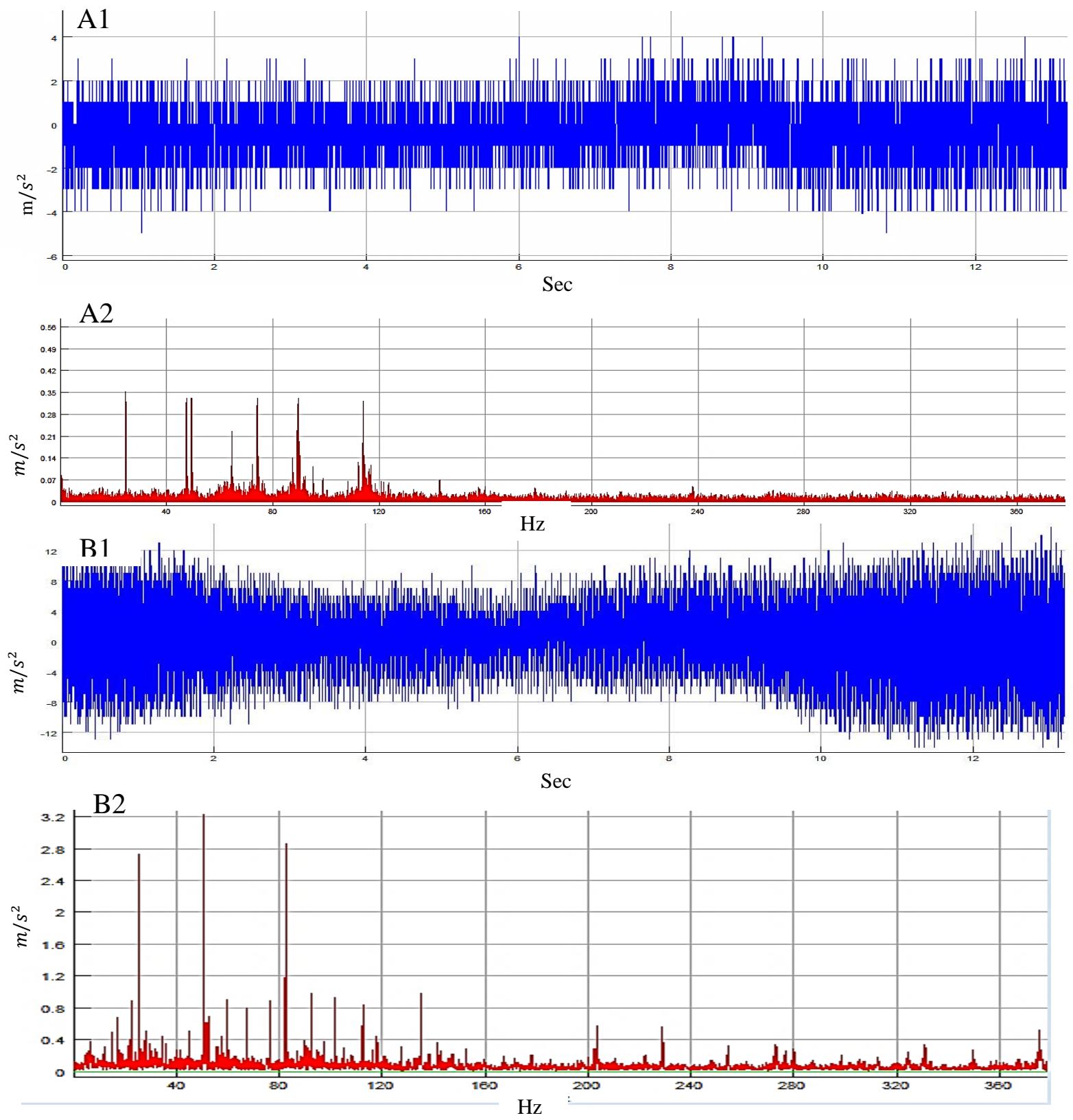

Figure 3: Experimental results of: Good condition (A1 time domain waveform, A2 frequency domain), faulty condition (B1 time domain waveform, B2 frequency domain). 


\section{AL-QADISIYAH JOURNAL FOR \\ ENGINEERING SCIENCES}

Vol. 10 , No. 4

ISSN: $1998-4456$

\section{VIBRATION MEASUREMENT TEST}

Three cases of change parameters each one has four results which will be existed the dynamic response of change each parameter separately, the following table illustrates the methodology. Where: $(\mathrm{C})$ the center distance between drive and driven shafts, $(\mathrm{I})$ radius ratio, $(\mathrm{N})$ rotating speed of motor in rpm, (Ti) initial belt tension.

Table 2: Methodology of obtaining results.

\begin{tabular}{|c|l|l|c|c|c|c|}
\hline Cases & $\begin{array}{l}\text { Change } \\
\text { parameter }\end{array}$ & $\begin{array}{l}\text { Constant } \\
\text { parameters at } \\
\mathrm{T}_{\mathrm{i}}=30 \mathrm{~N}\end{array}$ & $\mathrm{~A}$ & $\mathrm{~B}$ & $\mathrm{C}$ & $\mathrm{D}$ \\
\hline 1 & $\begin{array}{l}\text { Rotating } \\
\text { Speed rpm }\end{array}$ & $\begin{array}{l}\mathrm{C}=37 \mathrm{~cm} \\
\mathrm{I}=1: 1\end{array}$ & 500 & 1000 & 1500 & 2000 \\
\hline 2 & $\begin{array}{l}\text { Center } \\
\text { distance cm }\end{array}$ & $\begin{array}{l}\mathrm{N}=1500 \mathrm{rpm} \\
\mathrm{I}=1: 1\end{array}$ & 37 & 47 & 57 & 67 \\
\hline 3 & $\begin{array}{l}\text { Reduction } \\
\text { ratio }\end{array}$ & $\begin{array}{l}\mathrm{C}=37 \mathrm{~cm} \\
\mathrm{~N}=1500 \mathrm{rpm}\end{array}$ & $1: 1$ & $1: 1.5$ & $1: 2$ & $1: 2.5$ \\
\hline
\end{tabular}

It is necessary to check belt-resonance state which in FFT shows high peaks at $1 \mathrm{X}$ in the radial directions. $18 \mathrm{~N}$ initial tension, $1500 \mathrm{rpm}(25 \mathrm{~Hz}), 10 \times 10 \mathrm{~cm}$ pulleys diameters, and center distance $37 \mathrm{~cm}$. figure below of stroboscope camera picture shows belt resonance state. Resonance state depends on belt initial tension, center distance and rotating speed.

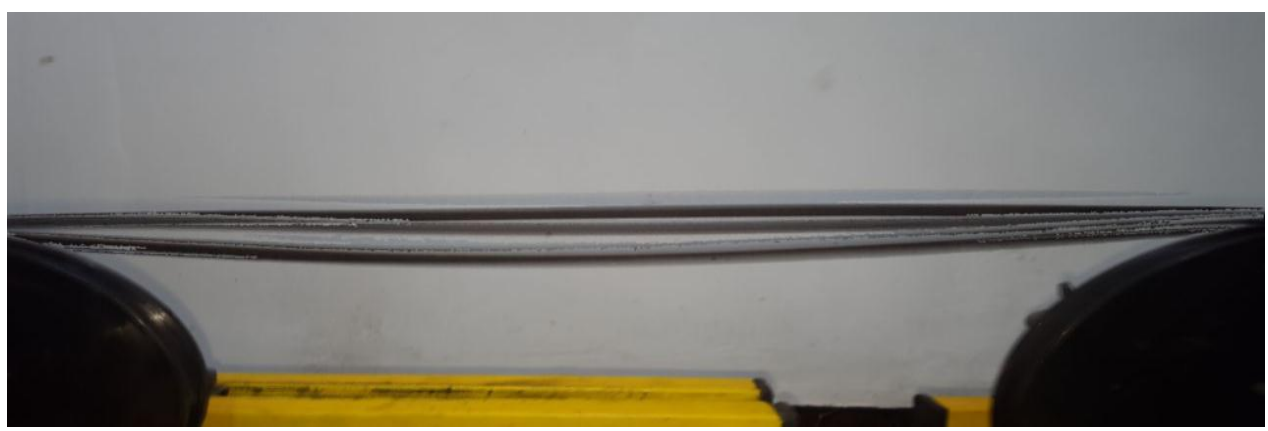

Figure 4: stroboscope camera picture shows belt resonance.

\section{RESULTS AND DISCUSSIONS}

\section{Case 1:- running speed changes :}

Figures (5),(6),(7) show response due to rpm increases at $(X, Y, Z)$ direction respectively, meanwhile the results show general increase in any peak of each founded fault as rpm increase, and it gave high increase in horizontal directions $\left(X_{1}, X_{2}\right)$. 

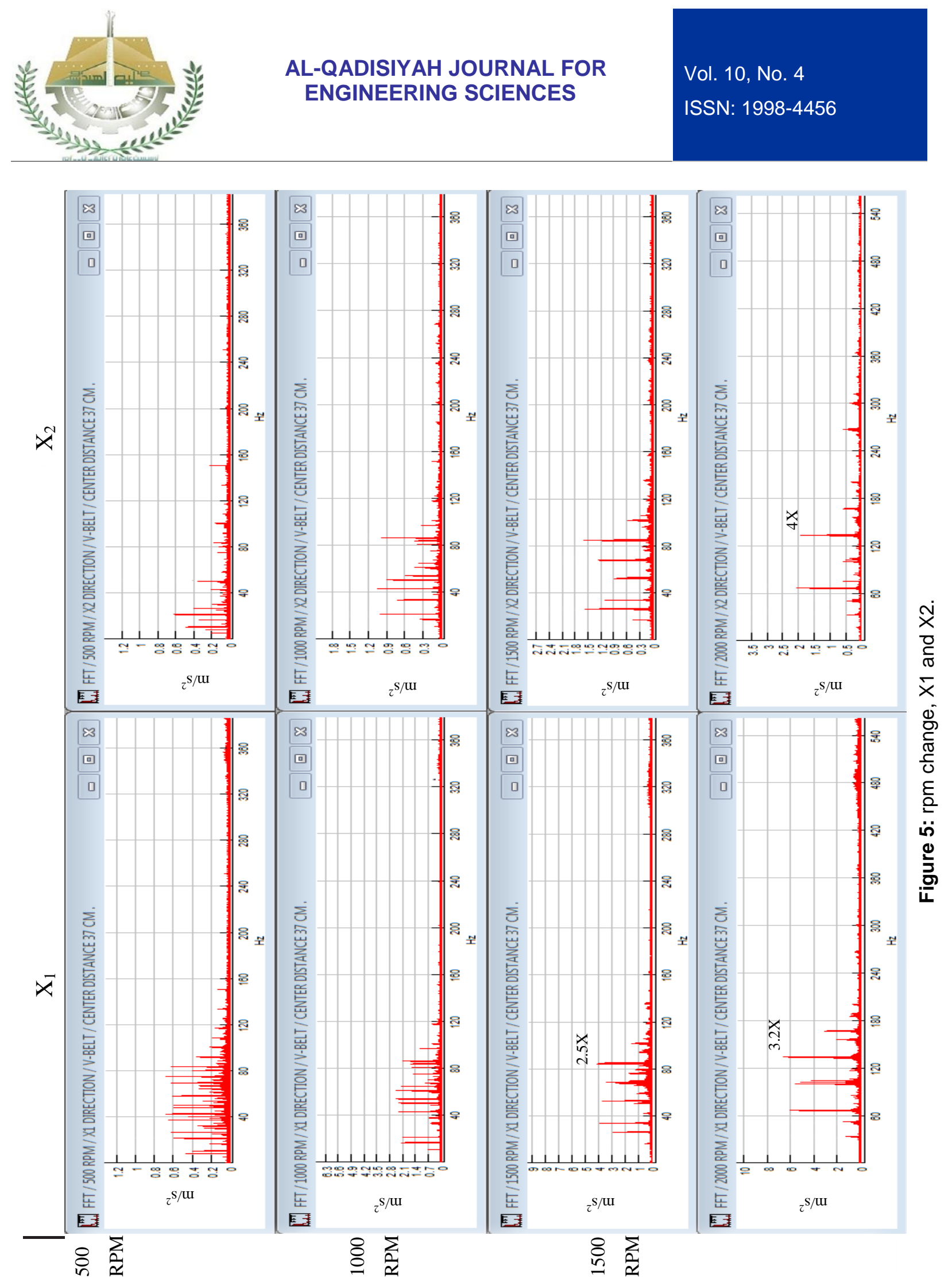

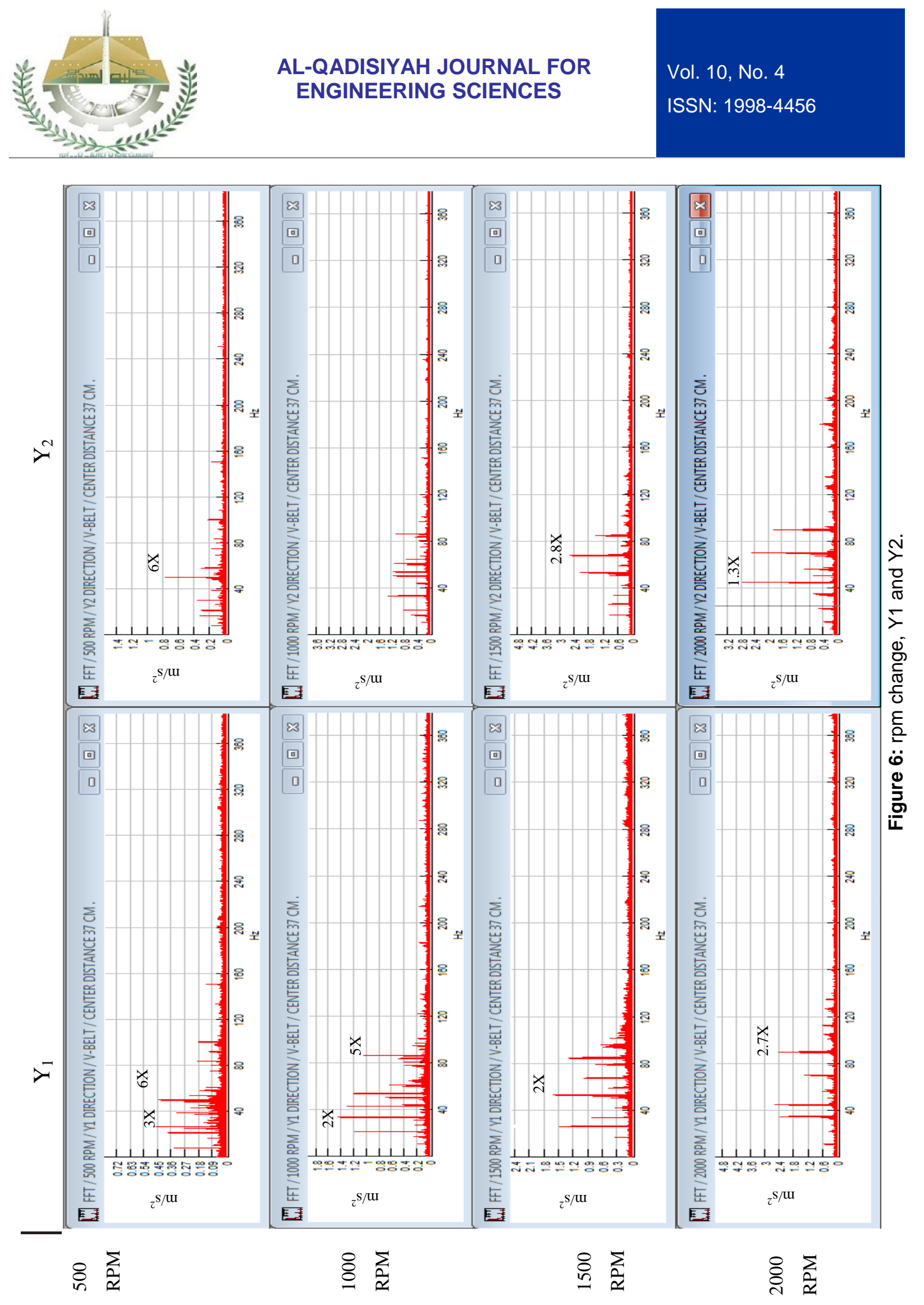

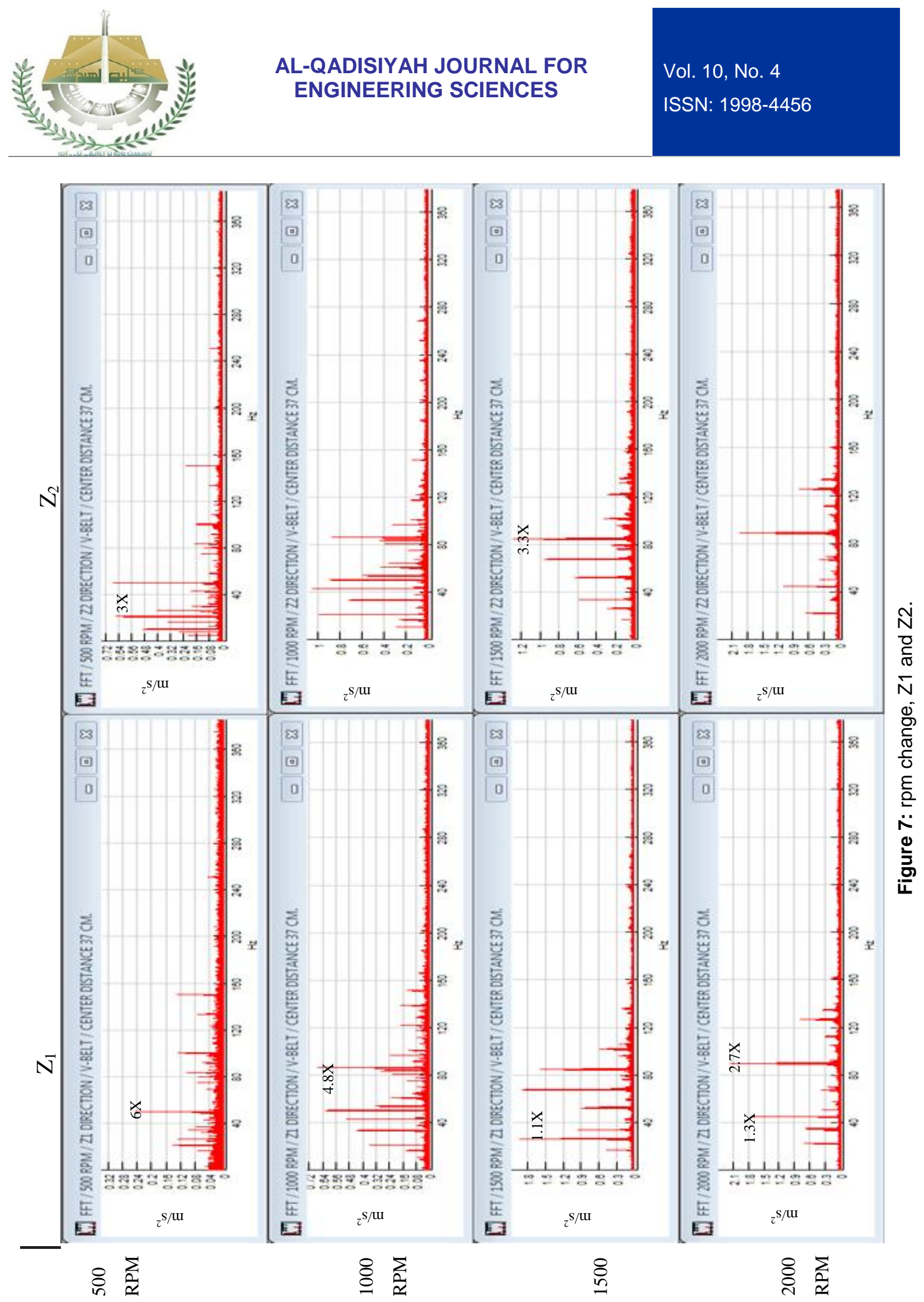


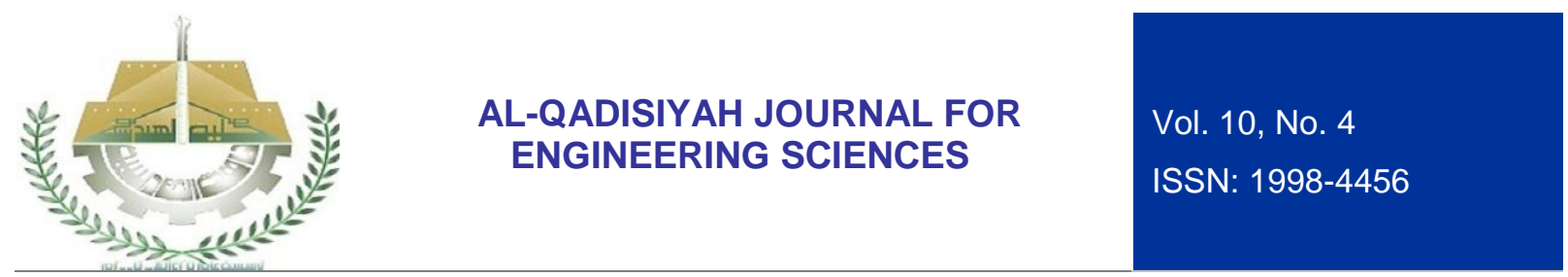

Case 2:- center distance changes:

Figures (7), (8), (9), shows increasing in vibration due to increase length of belt (center distance), and there is signification change in FFT peaks due the change center distance cases with center distance values: $(37,47,57,67) \mathrm{cm}$, this behavior happened while no resonance state done in the conditions of (1500 rpm, pulleys $10 \times 10 \mathrm{~cm}$, initial tension $30 \mathrm{~N}$ ) at above center distance.

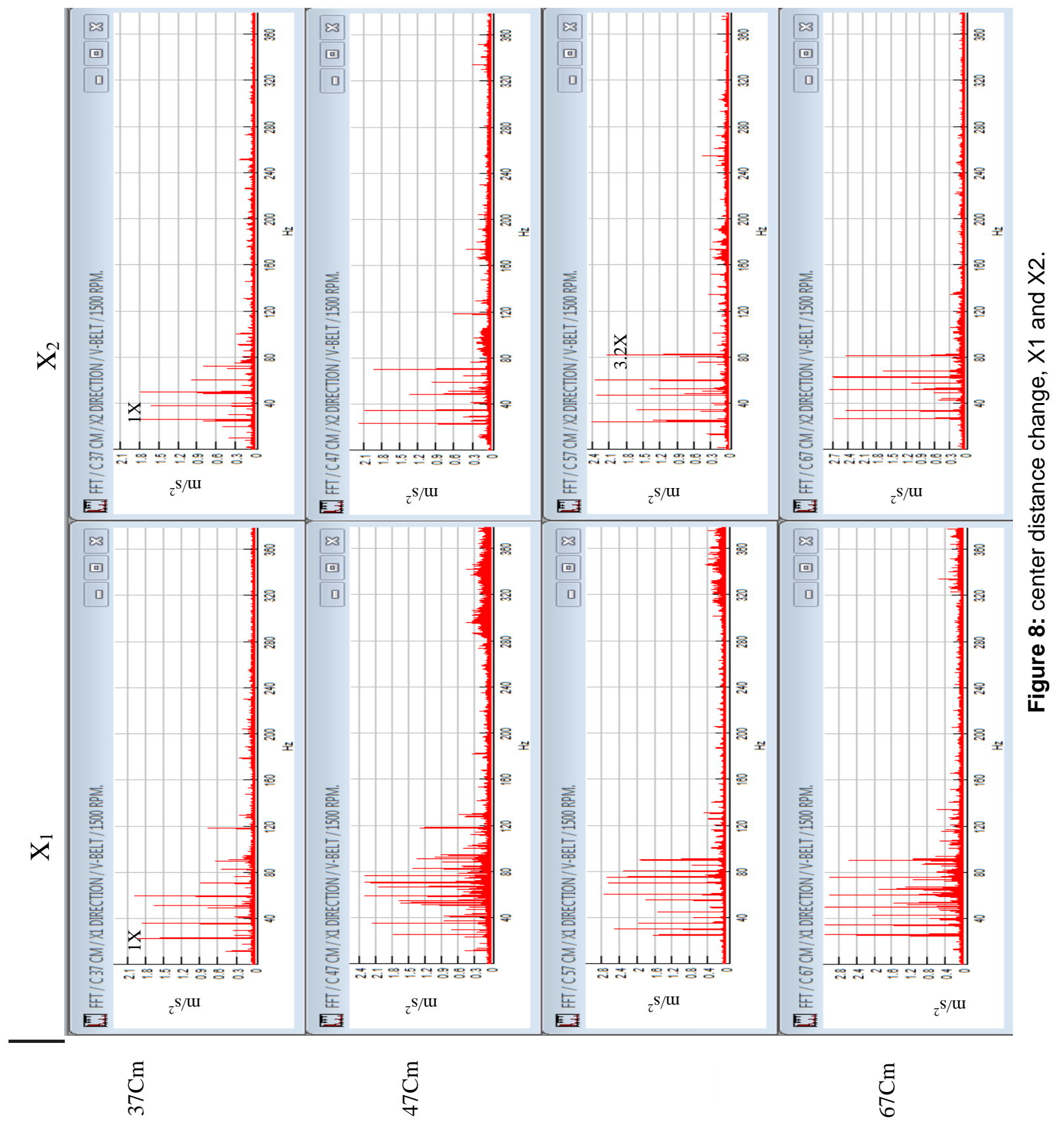



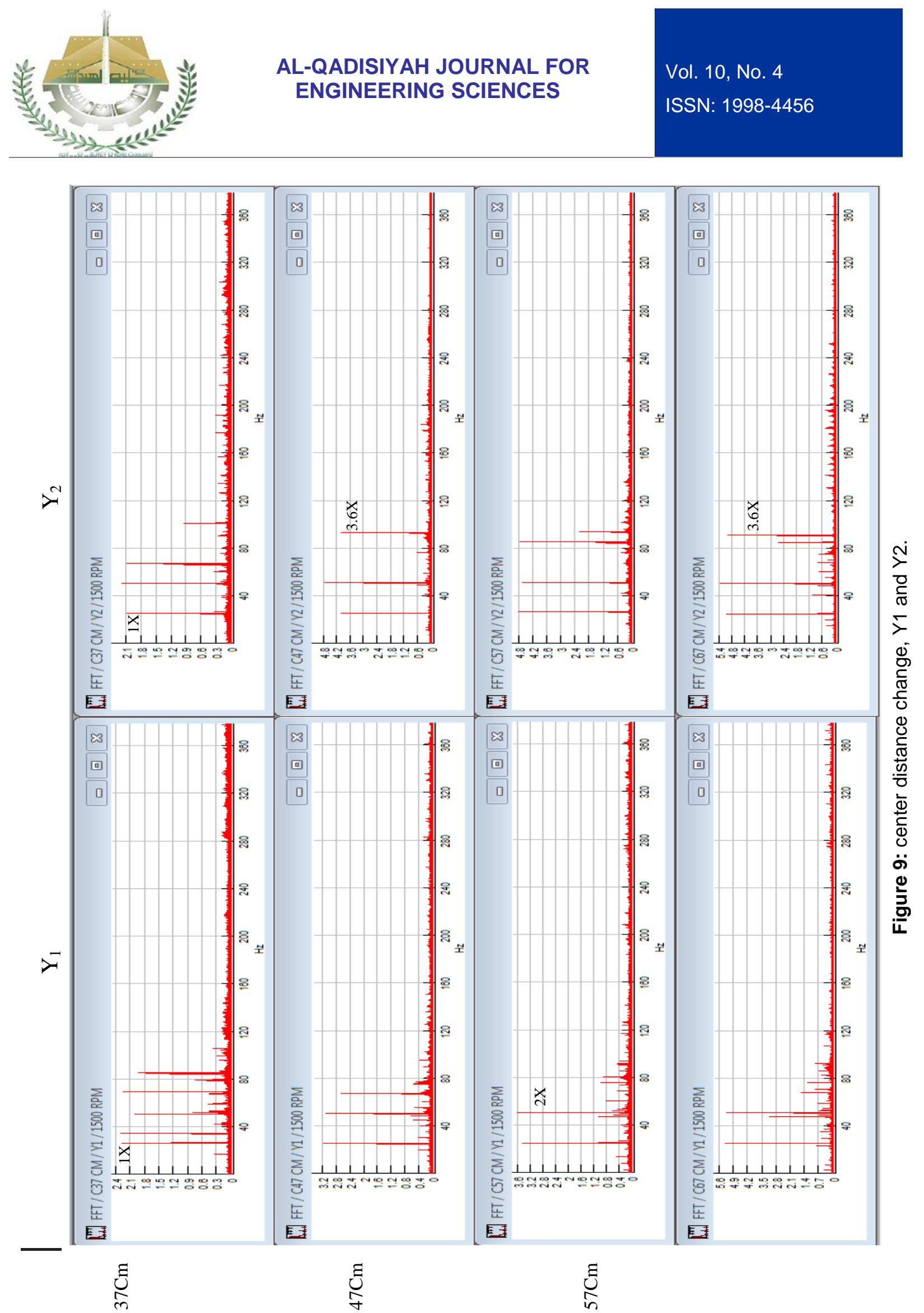

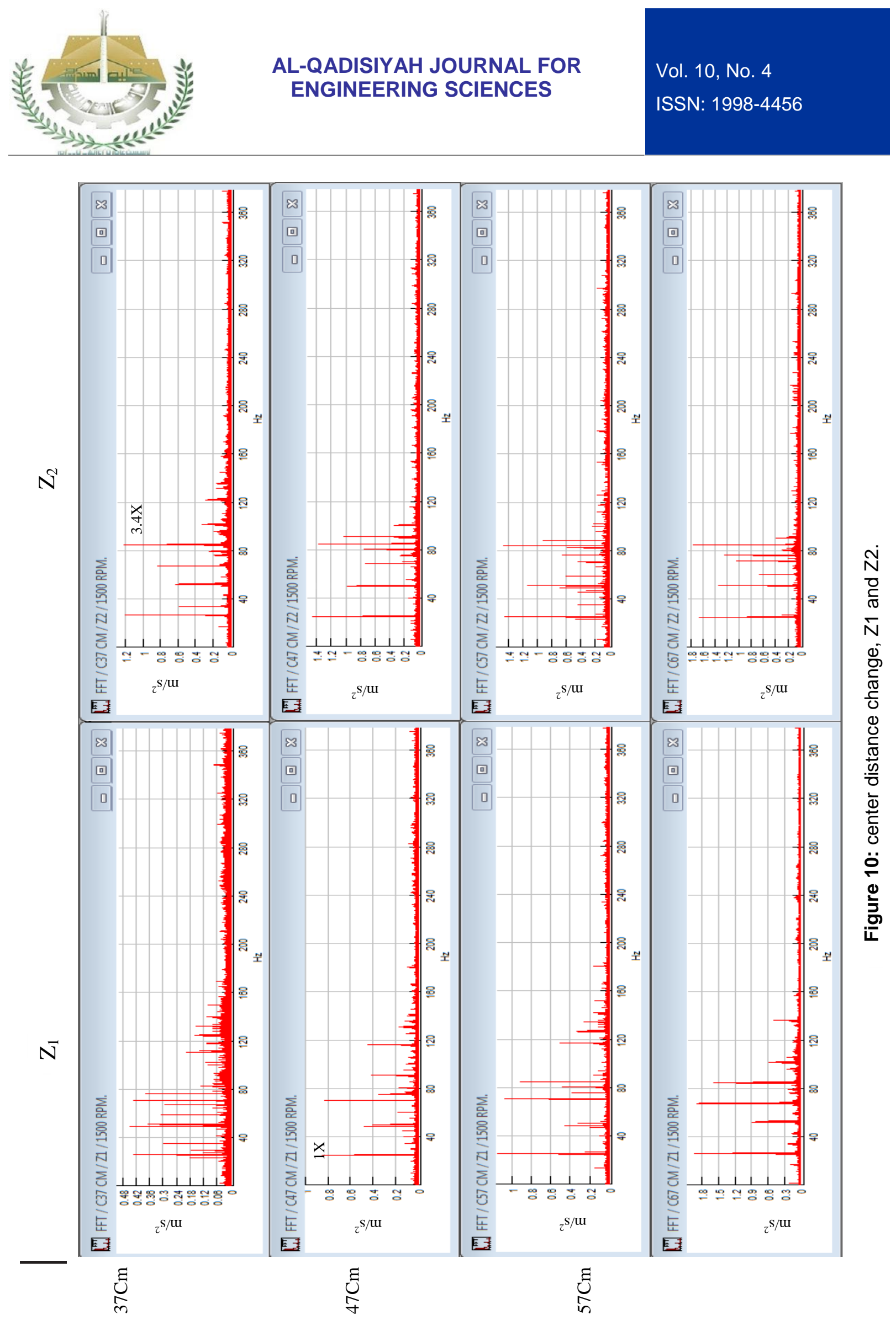

Page 585 Copyright @ 2017 Al-Qadisiyah Journal For Engineering Sciences. All rights reserved. 


\section{AL-QADISIYAH JOURNAL FOR ENGINEERING SCIENCES}

\section{Case 3:- reduce ratio changes:}

Where drive pulley diameter value is $10 \mathrm{~cm}$ and driven pulleys diameters are $(10,15,20,25) \mathrm{cm}$, and drive speed of $1500 \mathrm{rpm}(25 \mathrm{~Hz})$ with driven pulleys speed of $(1500,1000,750,600) \mathrm{rpm}$ which means $(25$, 16.66, 12.5, 10) Hz; results presented no signification change in $\left(X_{1}, Y_{1}, Z_{1}\right)$ directions as figures (11), (12), (13), shown. But there is general decrease in acceleration peaks at $\left(X_{2}, Y_{2}, Z_{2}\right)$ due to rpm reduce and diameter increase (diameter ratios increase $(1,1.5,2,2.5)$.
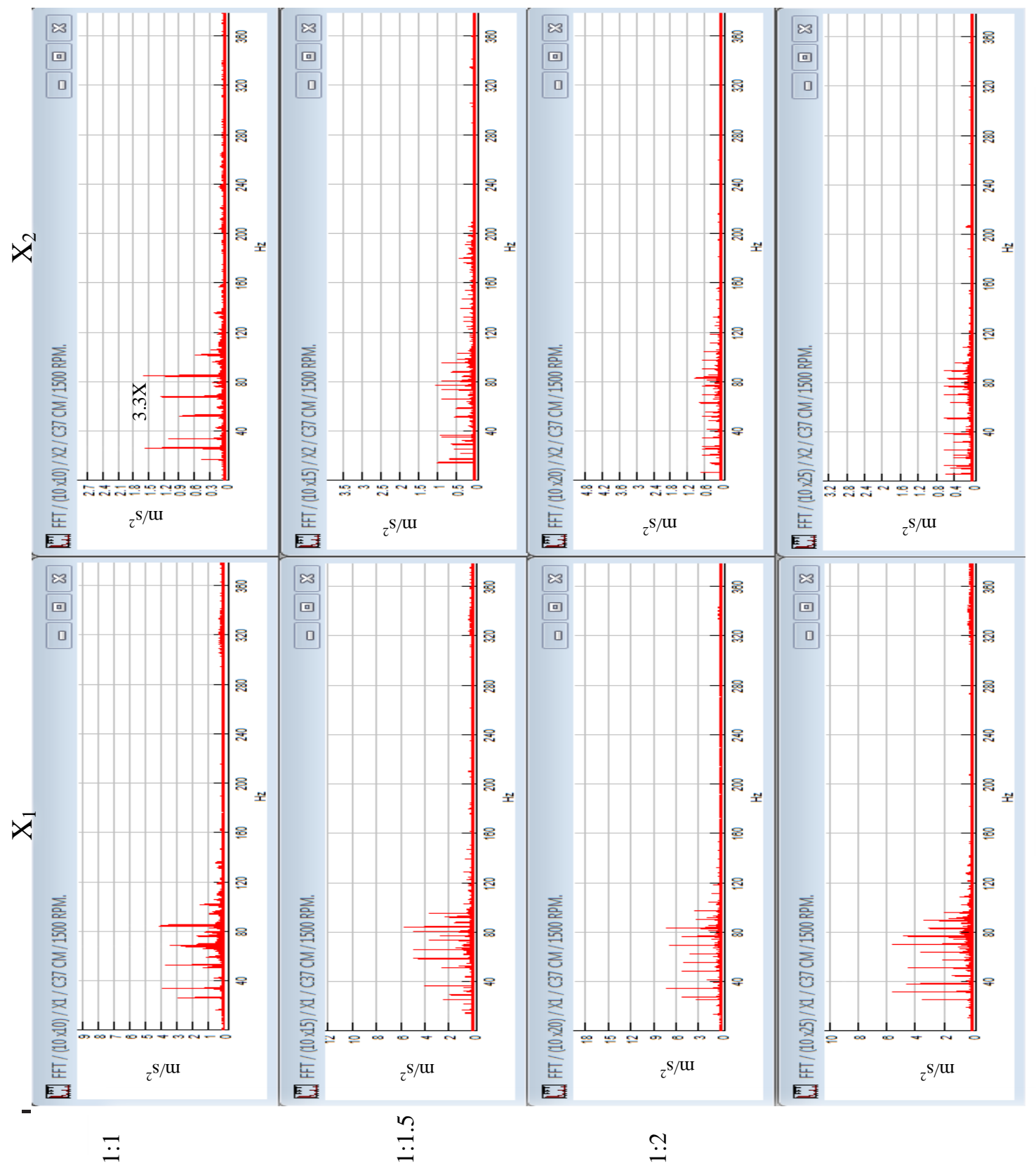

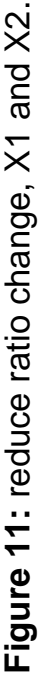



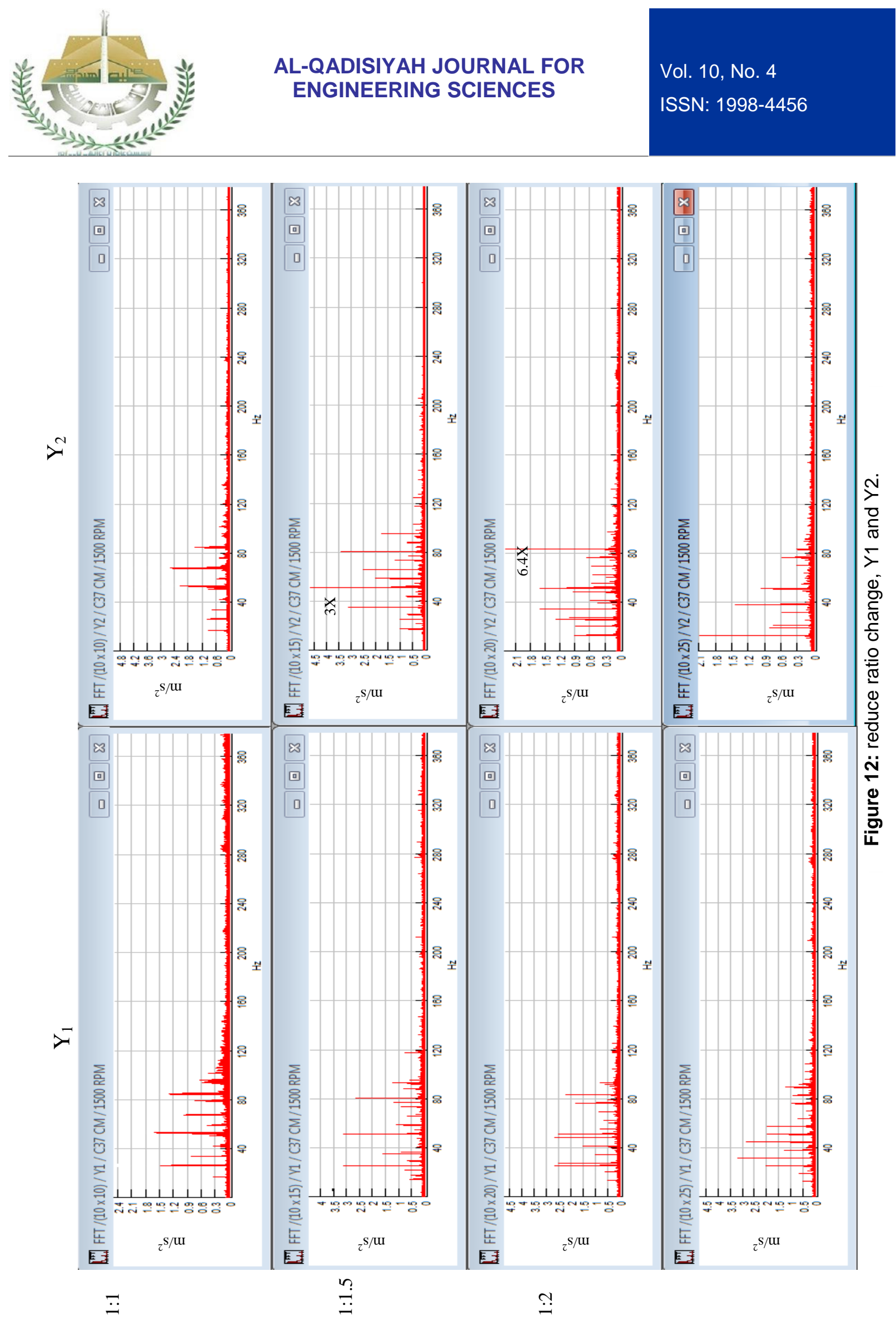

Copyright @ 2017 Al-Qadisiyah Journal For Engineering Sciences. All rights reserved. 

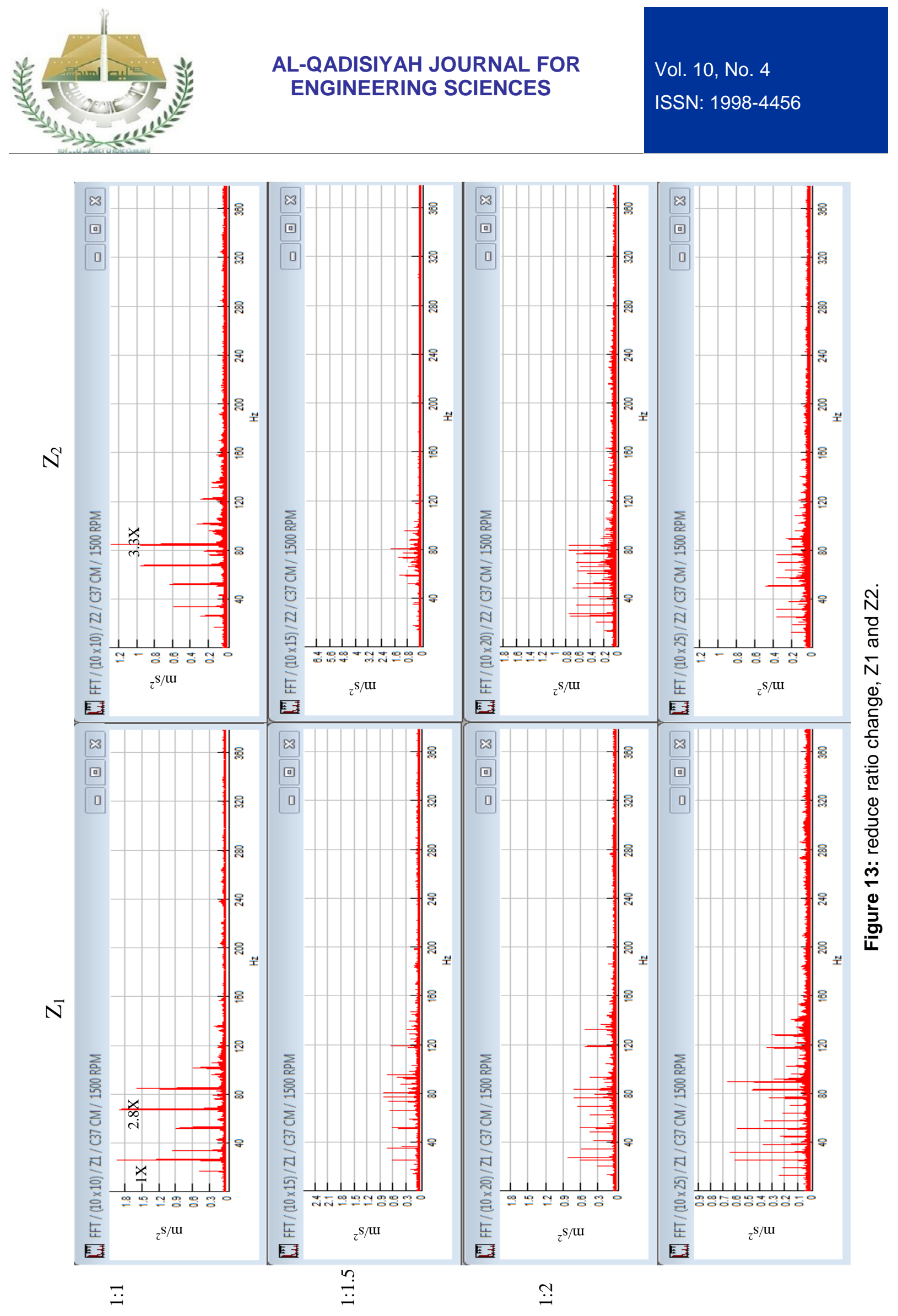

Copyright $\odot 2017$ Al-Qadisiyah Journal For Engineering Sciences. All rights reserved. 


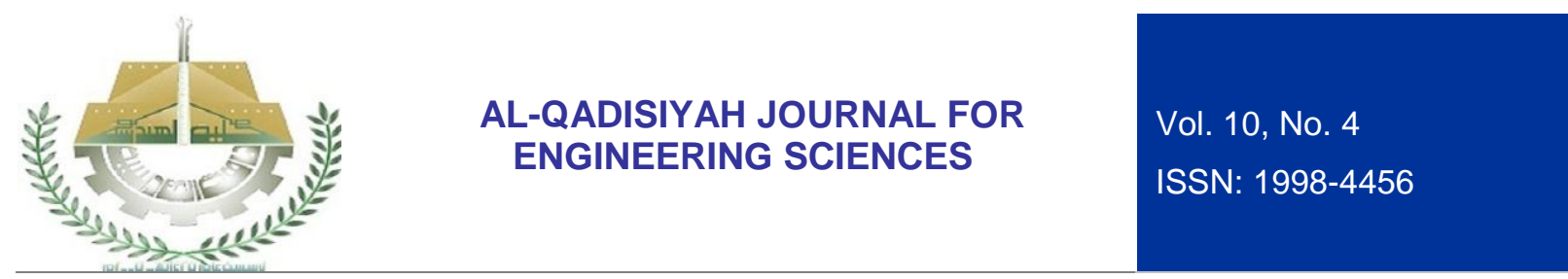

CONCLUSION

By analyzing the results graphs it may be concluded that the intensity of vibration changed in some cases and no intelligible changes in other cases as parameters manipulate, accordingly some results show significant changes at some or all axis while some results not affected. Figures (5),(6),(7) of case 1, show response due to rpm increases, the (acceleration-frequency) graph in figure (5) present the (accelerationfrequency) graphs from sensor 1 at $X_{1}$ direction, the affected region started from (0 to 180) $\mathrm{Hz}$ on the horizontal axis of graph (frequency axis) where some peaks of acceleration appears with maximum values $(0.6,2.1,4,6) \mathrm{m} / \mathrm{s}^{2}$ corresponding to $(500,1000,1500,2000) \mathrm{rpm}$ respectively. Nearly, the obtained results from sensor 2 at $X_{2}$ direction are same. Figure (6) show from $Y_{1}$ direction the affected region starting from $(0$ to 80$) \mathrm{Hz}$ of frequency axis producing some peaks of acceleration with maximum values about $(0.45,1.4,1.8$, 2.4) $\mathrm{m} / \mathrm{s}^{2}$ corresponding to $(500,1000,1500,2000) \mathrm{rpm}$ respectively. While for the same region at the obtained graphs from sensor 2 at $Y_{2}$ direction for the same sequence of rpm the maximum values of peaks of acceleration were $(0.8,1.2,2.4,2.8) \mathrm{m} / \mathrm{s}^{2}$ respectively. Figure (7) show from sensor 1 in $Z_{1}$ direction the effected region started from $(0$ to 160$) \mathrm{Hz}$ in the frequency axis, produce some peaks of acceleration with maximum values about $(0.24,0.64,1.8,2.1) \mathrm{m} / \mathrm{s}^{2}$ corresponding to the same sequence rpm, while for the same region at graphs obtained from sensor 2 in $Z_{2}$ direction maximum peaks values where about $(0.64,1$, $1.2,1.8) \mathrm{m} / \mathrm{s}^{2}$.

From the above results and the behavior of vibration noticed in FFT graphs, it can be considering that the increasing in rpm cause increases in the number of acceleration peaks and in the value of these peaks. In the higher speeds small difference occurs between the two sensors readings because of the direction of rotation and sensor 2 location on driven pulley (in the end of belt).

In Case 2, figures (8,9 and 10), shows noticeable response due to the increase in length of belt (center distance), from sensor 1 the affected region starts from $(0$ to 100$) \mathrm{Hz}$ on the frequency axis which produce some peaks of acceleration with the maximum values of $(2,2.3,2.8,3.1) \mathrm{m} / \mathrm{s}^{2}$ in $X_{1}$ direction, $(2.3$, $3.2,3.6,5.2) \mathrm{m} / \mathrm{s}^{2}$ in $\mathrm{Y} 1$ direction, and $(0.45,0.85,1.2,1.95)$ in $\mathrm{Z} 1$ direction corresponding to selected center distance values of $(37,47,57,67) \mathrm{cm}$. the resulted graphs from sensor 2 for same affected region were $(1.8$, $2.1,2.4,2.7) \mathrm{m} / \mathrm{s}^{2}$ in $X 2$ direction, $(2.1,4.8,4.85,5.4) \mathrm{m} / \mathrm{s}^{2}$ in $Y 2$ direction, and $(1.2,1.4,1.5,1.8) \mathrm{m} / \mathrm{s}^{2}$ corresponding to selected center distance values of $(37,47,57,67) \mathrm{cm}$. Hence, from the above FFT graphs results it can be considering that the increase in the center distance between the two pulleys (belt length) will cause increases in the acceleration peaks values (vibration) which agree with the theoretical concepts of pulley-belt systems.

In Case 3, drive pulley diameter value fixed on $10 \mathrm{~cm}$ and driven pulleys diameters values have a sequence increase as $(10,15,20,25) \mathrm{cm}$, with drive speed of $1500 \mathrm{rpm}(25 \mathrm{~Hz})$, while driven pulleys speed were $(1500,1000,750,600) \mathrm{rpm}$ which means $(25,16.66,12.5,10) \mathrm{Hz}$ due to the increase in diameter ratio values. Figures $(\mathbf{1 1 , 1 2}$ and $\mathbf{1 3})$ shows noticeable response due to the increase in driven pulley diameter values (diameter ratio), from sensor 1 (located on drive pulley bearing) the affected region in FFT graphs starts from (0 to 150) $\mathrm{Hz}$ on the frequency axis which produce some peaks of acceleration with the maximum values of $(4,4.8,8,6) \mathrm{m} / \mathrm{s}^{2}$ in $\mathrm{X} 1$ direction, $(1.5,3,2.6,3.2) \mathrm{m} / \mathrm{s}^{2}$ in $\mathrm{Y} 1$ direction, and $(1.9,0.9,0.8,0.65)$ in $\mathrm{Z} 1$ direction corresponding to selected diameter ratio values of $(1: 1,1: 1.5,1: 2,1: 2.5)$. The resulted FFT graphs from sensor 2 (located on driven pulley bearing) for same affected region were $(1.5,1,0.8,0.6) \mathrm{m} / \mathrm{s}^{2}$ in X2 direction, $(2.5,4.5,2.1,2.1) \mathrm{m} / \mathrm{s}^{2}$ in $\mathrm{Y} 2$ direction, and $(1.3,1.6,0.8,0.5) \mathrm{m} / \mathrm{s}^{2}$ in Z2 direction, corresponding to same selected diameter ratio values.

From above results it can be notice at diameter ratio of $(1: 1)$ that the both sensors gave a close values nearly. But during the sequence increase in driven pulley diameter values (diameter ratio) an decreases in acceleration peaks values occurs, this lead to consider that the increase in diameter ratio will cause a decrease in vibration especially on driven pulley. 


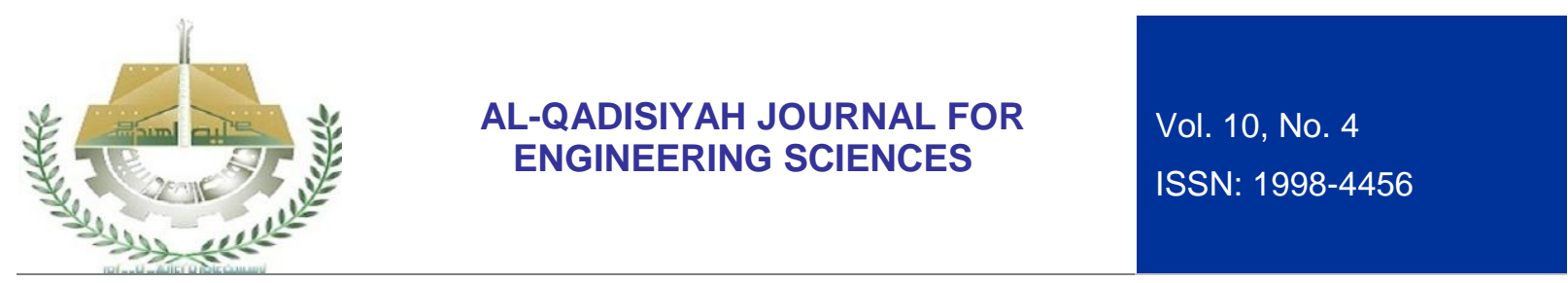

Resonance fault should be investigated during system operation by stroboscope camera as Figure (4) shown, then the critical values of speed ratio and center distance which cause the resonance case can be avoided.

If there is any faults related to pulleys, belts, shafts and bearings it will be noticed clearly by the FFT spectrum above figures, then it will be detected by analyzing this indicated figure in order to make correction by maintenance processes.

REFERENCE

1. Hu Ding, "Periodic responses of a pulley belt system with one-way clutch under inertia excitation" journal of sound and vibration. pp. 308-328, 353 (2015).

2. Chowdhury, "Dynamic response of machine foundations considering soil damping and embedment" Petrofac Int.Ltd. September 2011.

3. Chitresh Nayak, Vimal Kumar Pathak, Sagar Kumar. Prashant Athnekar, "design and development of machine fault simulator (MFS) for fault diagnosis", International Journal of Recent advances in Mechanical Engineering (IJMECH) Vol.4, No.4, pp.77-84, November 2015.

4. Gregor Cepon, LionelManin, MihaBoltezara, "Introduction of damping into the flexible multi- body beltdrive model: A numerical and experimental investigation “, Journal of Sound and Vibration 324, pp.283-296, February 2009.

5. Chyuan-Jau Shieh, Wen-Hwa Chen, "Effect of angular speed on behavior of a V-belt drive system", International Journal of Mechanical Sciences 44, pp.1879-1892, June 2002.

6. Abdulrahman Abdulshakoor Al Bulushi, G.R. Rameshkumar and M. Lokesha, "Fault Diagnosis in Belts using Time and Frequency based Signal Processing Techniques" International Journal of Recent advances in Mechanical Engineering,Vol.6,No.11,pp.11-20, November 2015.

7. Mouleeswaran Senthilkumar, Moorthy Vikram and Bhaskaran Pradeep, "Vibration Monitoring for Defect Diagnosis on a Machine Tool: A Comprehensive Case Study", International Journal of Acoustics and Vibration, Vol. 20, No. 1, pp.4-9, February 2015.

8. S.Ojha, D. Sarangi, B.K. Pal, B.B. Biswal, " Performance Monitoring of Vibration in Belt Conveyor System", Journal of Engineering Research and Applications, Vol. 4, Issue 7(Version 6), pp.22-31, July 2014.

9. S. R. Algule, D. P. Hujare, "Experimental Study of Unbalance in Shaft Rotor System Using Vibration Signature Analysis", International Journal of Emerging Engineering Research and Technology, Vol.3, Issue 4, PP 124-130, April 2015.

10. Puneet Bansal, I. S. Rajay Vedaraj," Monitoring and Analysis of Vibration Signal in Machine Tool Structures", International Journal of Engineering Development and Research, Vol. 2, Issue 2, pp.2310-1317, 2014.

11. B. Kiran Kumar, G. Diwakar, Dr. M. R. S. Satynarayana, " Determination of Unbalance in Rotating Machine Using Vibration Signature Analysis", International Journal of Modern Engineering Research, Vol.2, Issue.5, pp-3415-3421, Sep-Oct. 2012.

12. Pravesh Durkhure, Akhilesh Lodwal, " Fault Diagnosis of Ball Bearing using Time Domain Analysis and Fast Fourier Transformation", International Journal of Engineering sciences and research technology, pp.711715, July 2014.

13. Arko Djajadi, Arsi Azavi, Rusman Rusyadi, Erikson Sinaga, "Monitoring vibration of amodel of rotating machine", Journal of Mechatronics, Electrical Power, and Vehicular Technology, Vol. 02, No 1, pp 51-56, 2011.

14. Sakshi Kokil, Prof. S. Y. Gajjal, Assist. Prof. M. M. Shah, Prof. S. D. Kokil, " International Journal of Engineering Research \& Technology, Vol. 3 Issue 8, pp.859-866, August 2014.

15. Dimitris C. Tsantiotis, Theodore N. Costopoulos, and Ioannis S. Zotos, "Maintenance of Mechanical Drivers and Fault Diagnosis of Machine Elements", 2nd International Conference "From Scientific Computing to Computational Engineering", 2nd IC-SCCE Athens, 5-8 July, 2006.

16. ADXL335 data sheet, https://www.sparkfun.com/datasheets/Components/SMD/adxl335.pdf.

17. C. Scheffer PhD, MEng, SAIMechE, "Practical Machinery Vibration Analysis and Predictive Maintenance" chapter 5, p.89, first published 2004. 